\title{
Treating Helicobacter pylori induced ulcers with antibiotics alone
}

Infection of the stomach and proximal duodenum with Helicobacter pylori induces inflammation with associated changes in the mucosa. Alterations in mucus structure and function, surface epithelial cell integrity, mucosal blood flow, and local mucosal neural and hormonal status have been observed following this infection. A proportion of subjects infected with $H$ pylori develop duodenal ulcer disease. ${ }^{1}$ The mechanism of ulcer formation is currently unclear; postulated agents include bacterial factors (urease, phospholipase, proteases, toxins) and the products of inflammation (cytokines, nitric oxide, oxygen radicals). Islands of gastric metaplasia infected with $H$ pylori, along with other factors such as production of excessive gastric acid and exogenous agents, such as nonsteroidal anti-inflammatory drugs, create an environment in which ulceration will occur. Ulcer healing is a very complex process comprising restitution of the mucosal surface which involves epithelial cells and adjacent connective tissues. Re-epithelialisation and reconstruction of epithelial structures is under the control of local growth factors, particularly epidermal growth factor. Formation of granulation tissue involves connective tissue cell growth, controlled by fibroblast growth factors, and microvascular changes, with angiogenesis also regulated by growth factors.

Factors that have previously been suggested to be important in delayed or impaired ulcer healing include smoking, ulcer size, and ulcer site. ${ }^{2}$ Lam and colleagues, in this issue (see page 43), have shown that an antibiotic only regimen (metronidazole, amoxycillin and clarithromycin) when given for two weeks healed duodenal ulcer, resulting in a $92.5 \%$ cure rate at four weeks after treatment. An important observation was the fact that clearance, as well as eradication, of $H$ pylori contributed significantly to ulcer healing. Other contributing factors included ulcer size. An interesting additional aspect was that symptoms improved in those treated with the antibiotic regimen, although this was not statistically significant. In this study, as in others, the placebo treatment healing rate at 12 weeks was $63.4 \%$, compared with a $100 \%$ healing rate in the antibiotic treated group at the same period.

This is an important study which shows that healing of duodenal ulcer disease is dependent on clearance and eradication of $H$ pylori. Of interest is the fact that ulcer healing occurred in the placebo treated group without bacterial clearance or eradication. In addition, ulcers also healed in subjects treated with antibiotics in whom the infection persisted. Several previous studies of antibiotics given in combination with other ulcer healing agents compared with the ulcer healing agent alone, have produced similar findings. ${ }^{3-6}$ The possibility that ulcer healing is induced by antibiotics via mechanisms other than elimination of infection is intriguing. Evidence supporting this observation relates to the gastric cytoprotective properties of a number of antibiotics, including amoxy- cillin, metronidazole and clarithromycin in animal models. Metronidazole and furazolidone have been reported to have success in healing of peptic ulcer when administered alone to humans. ${ }^{78}$ In the acetic acid induced rat ulcer model, penicillin and streptomycin accelerated ulcer healing. ${ }^{9}$ The influence of antibiotics which suppress $H$ pylori on gastric acid secretion and the intraduodenal $\mathrm{pH}$ is unknown. Similarly, the effect on duodenitis and inflamed gastric metaplastic mucosa is unclear.

Ulcer healing may be achieved by inhibition of gastric acid secretion, suppression of $H$ pylori induced inflammation, and the use of surface active agents (for example, sucralfate, colloidal bismuth subcitrate). These latter agents may act in part by an effect on $H$ pylori. In addition, spontaneous ulcer healing does occur without treatment. The observations that $H$ pylori clearance and eradication are important in the healing of ulcers raises a number of important issues. Treatment of $H$ pylori infection at the time of the initial ulcer diagnosis is essential to achieve ulcer healing, ${ }^{6}$ to diminish symptoms more rapidly, ${ }^{10}$ to prevent complications and to prevent relapse. The duration and form of treatment must now be reviewed in light of our current understanding of the role of antibiotics and $H$ pylori in ulcer disease. Currently, the most effective regimens used to eradicate this infection incorporate ulcer healing agents in the form of colloidal bismuth subcitrate, $\mathrm{H}_{2}$-receptor antagonists, ranitidine bismuth citrate, or proton pump inhibitors. These agents have been administered for one to two weeks and are often followed by acid suppressive treatment. The need for this additional treatment must now be re-evaluated. In uncomplicated duodenal ulcer disease our current understanding would suggest that treatment should be given for no more than two weeks. Therapies should be effective and achieve cure of $H$ pylori in more than $80 \%$ of all patients treated. Posttreatment assessment of $H$ pylori status is required as a predictor of ulcer cure.

It is now clear that $H$ pylori induced changes are important in the pathogenesis of ulcer disease and specific treatment achieves ulcer healing. Currently used regimens incorporating traditional anti-ulcer agents should be continued because of their known efficacy and safety. Well designed studies looking at the cost-benefit of the different helicobacter treatment regimens, using the endpoints of symptom responses and healing of ulcers, are advocated. Additional research is required to assess the mechanisms of ulcer healing in light of this new knowledge.

Director of Medicine/Gastroenterology,

JOHN LAMBERT

Monash University

Peninsula Health Care Network,

Hastings Road,

Frankston 3199

Victoria, Australia 
1 Lin SK, Lambert JR. Helicobacter pylori in ulcerogenesis. Scand $f$ Gastroenterol 1995; 95: 64-9.

2 Lam SK, Koo J. Accurate prediction of duodenal ulcer healing rate by discriminant analysis. Gastroenterology 1983; 85: 403-12

3 Bayerdorffer E, Kasper G, Pirlet T, et al. Ofloxacin in der Therapie Campylobacter pylori-positiver Ulcera Duodeni. Dtsch Med Wochenschr 1987; 112: 1407-11.

4 Graham DY. Lew GM, Evans DG, et al. Effects of triple therapy (antibiotics plus bismuth) on duodenal ulcer healing: A randomised controlled trial. Ann Intern Med 1991; 115: 266-9.

5 Marshall BJ, Goodwin CS, Warren JR, et al. Prospective double-blind trial of duodenal ulcer relapse after eradication of Campylobacter pylori Lancet 1988; ii: 1437-42.
6 Penston JG. Clinical aspects of Helicobacter pylori eradication therapy in peptic ulcer disease [review]. Aliment Pharmacol Ther 1996; 10: 469-86. 7 Diaz MQ, Escobar AS. Metronidazole versus cimetidine in the treatment of gastroduodenal ulcer. Lancet 1986; i: 907 .

8 Zbeng ZT, Wang YB. Treatment of peptic ulcer disease with furazolidone. $f$ Gastroenterol Hepatol 1992; 7: 533-7.

9 Elliott SN, Wallace JL. Nitric oxide, bacteria and ulcer healing in Helicobacter pylori. In: Hunt RH, Tytgat GNJ, eds. Basic mechanisms to clinical care. Amsterdam: Kluwer Academic Publishers, 1996: 132-8.

10 Phull PS, Ryder SD, Halliday D, Price AB, Levi AJ, Jacyna MR. The economic and quality-of-life benefits of Helicobacter pylori eradication in chronic duodenal ulcer disease - a community-based study. Postgrad Med f 1995; 77: 413-8. 